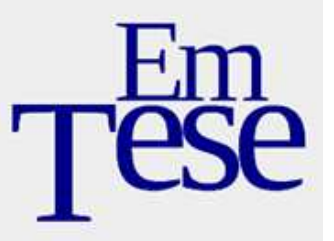

\title{
Relação entre a Federação das Indústrias do Espírito Santo e o governo de Christiano Dias Lopes (1967-1971)
}

Ciro Campelo Oliveira ${ }^{1}$

\section{Introdução}

O presente artigo tem como objetivo analisar a participação da Federação das Indústrias do Espírito Santo (Findes) na gestão do ex-governador capixaba Christiano Dias Lopes (1967-1971). Para tratar da criação da Findes, é preciso analisar o contexto político e econômico em que se encontrava o Estado do Espírito Santo no final da década de 1950. Para tratar de seu desenvolvimento e sua inserção no executivo capixaba, é necessário perpassar pelos governos anteriores ao seu, bem como suas respectivas atuações no cenário capixaba até 1966, pois a criação e o desenvolvimento da Findes ocorre concomitante aos processos eleitorais e a sucessão das elites políticas que disputam a vaga do executivo capixaba.

Gramsci (1978) destaca a importância dos intelectuais na formação da cultura e sua influência na industrialização e na formação do técnico da indústria, nesse sentido, partimos de sua teoria para tratar da criação e atuação da Findes. Após sua formação e desenvolvimento, a Findes passa a interagir de forma estreita com o poder público, visando inserir-se no centro do poder executivo capixaba, buscando assim, ter seus interesses atendidos.

Todavia, o nosso problema se forma a partir da hipótese de Oliveira (2013), este aponta que a Findes funcionou como uma espécie de proto partido político durante o regime militar, servindo de base para formação de quadros políticos que viriam a

\footnotetext{
1 Mestrando no Programa de Pós Graduação em Sociologia Política na Universidade de Vila Velha. Bolsista da Capes. Graduado em História. Contato: ciro_campelo@hotmail.com
}

Em Tese, Florianópolis, v. 12, n. 1, jan./jul., 2015. ISSN: 1806-5023 


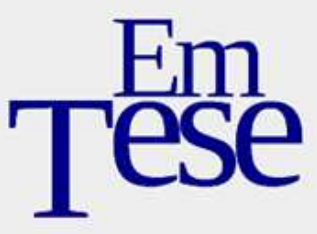

governar o Estado, processo que se inicia no governo de Rubens Rangel (1966-1967), se acentua no governo de Dias Lopes (1967/1971) e se concretiza na posse de Arthur Carlos Gerhardt em março de 1971, porém o nosso foco será no governo de Dias Lopes, onde a Findes passa a atuar de forma muito estreita, principalmente no sentido da formação do secretariado e na formulação do plano de governo, ao ponto de Dias Lopes ser chamado de "governador da Findes"; focamos também nesse governo por entender que ele foi a base dos governos posteriores. O governo Dias Lopes, abre espaço para a Findes, que compõe quadros importantes no seu secretariado e autarquias, mas também abre espaço para que esses quadros governem o Estado até o fim do Regime Militar.

\section{O Espírito Santo no contexto político-econômico (1945-1958) e o processo de criação da Findes}

Em 1945 o país reafirma seus ideais democráticos, encerrando assim 15 anos da ditadura Varguista no Brasil. Segundo Zorzal e Silva (1995, p. 155), a redemocratização do país, ocorrida em 1945, inaugura uma nova fase no processo de mudança do Estado brasileiro, posto que, a partir daí, o espaço político institucional é reaberto a uma maior participação da sociedade.

Com a constituição de 1946, se forma um novo sistema partidário no Brasil. Segundo Zorzal e Silva (1995) esse sistema se constitui a partir de quatro grupos heterogêneos, são eles: $1^{\circ}$ - Os Agrofundiários; $2^{\circ}$ - Mercantis Exportadores; $3^{\circ}$ Pequenos Proprietários Rurais; $4^{\circ}$ - Classes Populares Urbanas.

Analisar de forma detalhada a sucessão de quadros do executivo capixaba entre 1947 e 1954 foge ao escopo desse trabalho, pois nosso objeto de estudo é a Findes, principalmente a sua atuação a partir do regime militar, onde ocorre sua inserção definitiva no executivo capixaba. Os governos vão se sucedendo e o Partido Social

Em Tese, Florianópolis, v. 12, n. 1, jan./jul., 2015. ISSN: 1806-5023 


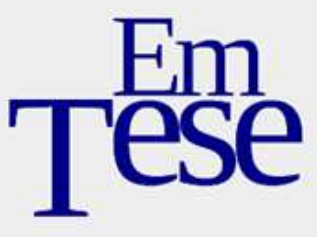

Democrata (PSD), após duas vitórias consecutivas (Carlos Lindenberg - 1947 e Jones dos Santos Neves em 1950), perdem o pleito de 1954 para Francisco Lacerda de Aguiar, o popular Chiquinho.

Os governos que antecederam Chiquinho estavam preocupados com a industrialização do Estado, principalmente Jones dos Santos Neves, porém com a vitória de Chiquinho, o Estado passa a ter um típico representante das forças agrofundiárias. Ora, Chiquinho era fazendeiro do interior do Estado e seu projeto para o Espírito Santo era de fortalecer a agricultura, a indústria era apenas uma atividade complementar.

Com a saída do PSD e de Jones do poder público capixaba, o projeto político para a industrialização do Espírito Santo é freado, mas não o projeto empresarial. Enquanto Chiquinho governava o Estado sem se preocupar, ou mesmo dar espaço as forças empresariais, o empresário Américo Buaiz se articulava para fazer valer o interesse dos empresários.

Ora, o Espírito Santo durante a primeira metade do século XX se apresenta basicamente como um Estado rural, sem uma grande massa urbana, não havia um setor industrial urbano e sua economia era baseada no setor primário, especificamente no cultivo do café, apoiada na pequena propriedade com mão de obra familiar. A posição socioeconômica era completamente desfavorável aos vizinhos do Sudeste: Rio de Janeiro, São Paulo e Minas Gerais. Do mesmo modo, o Espírito Santo não possuía força política e econômica comparado aos demais estados da região Sudeste, além de passar despercebido no mapa do Brasil, ficou alijado das decisões políticas e econômicas nacionais (RAINHA, 2012, p. 59).

Essa situação leva o Espírito Santo a uma posição indefinida e desfavorável, entre a prosperidade do Sudeste e a pobreza do Nordeste. Indefinida, pois não participava das capitalizações do Sudeste e desfavorável por que não participava das reivindicações do Nordeste.

Em Tese, Florianópolis, v. 12, n. 1, jan./jul., 2015. ISSN: 1806-5023 


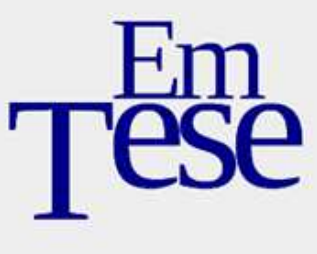

Mesmo em meados do Séc. XX, onde Rio e São Paulo, por exemplo, já estavam em adiantado processo de industrialização, o Espírito Santo não sediava nenhuma das 39 federações de sindicatos de empregadores. Esse quadro era prejudicial para o Estado, pois a existência de federações era imprescindível para atrair determinados recursos federais, não apenas isso, mas facilitava a inserção de empresários capixabas no contexto nacional (RAINHA, 2012, p. 59).

Para constituição de entidades sindicais era necessário um número mínimo de cinco sindicatos representantes de atividades ligadas ao setor, mas a sindicalização patronal no Espírito Santo era precária. Não era só do baixo desenvolvimento industrial que o estado se ressentia, mas também de uma massa de trabalhadores organizados. A ausência de trabalhadores altera a dinâmica das relações de força. Em outros estados o empresariado se constitui em meio aos trabalhadores, no Espírito Santo ocorre o inverso, o empresariado toma corpo sem qualquer reivindicação trabalhista, ou mesmo a necessidade de medir forças com a classe trabalhadora, isso gera um empresariado livre de pressões por parte dos trabalhadores e aparelhado ao Estado, aonde pode buscar seus interesses (RAINHA, 2012).

Podendo agir sem pressões trabalhistas, o empresariado encontra um Estado aberto as demandas privadas. Essa peculiaridade capixaba altera o caráter da relação Estado-Empresariado, os torna mais próximos e facilita a relação de interesses entre o setor público e privado.

Sendo assim, visando a criação de uma entidade de grau superior ligada à indústria, o empresário Américo Buaiz ${ }^{2}$ funda em 12 de fevereiro de 1958 a Federação das Indústrias do Espírito Santo (Findes) que passa a atuar de forma intensa no arcabouço político e econômico capixaba (GURGEL, 1998. p. 22).

\footnotetext{
${ }^{2}$ Filho de imigrantes libaneses, criou em 1943 a Buaiz Alimentos, se tornando empresa pioneira na área alimentícia no Espírito Santo, em 1958 por iniciativa própria cria a Findes.
}

Em Tese, Florianópolis, v. 12, n. 1, jan./jul., 2015. ISSN: 1806-5023 
Américo cria a Findes com o objetivo de organizar os empresários capixabas em uma entidade onde os mesmos pudessem ter seus interesses atendidos:

\begin{abstract}
Em fevereiro de 1958 é constituída a Federação das Indústrias do Espírito Santo por iniciativa da emergente fração de interesses industrializantes que, por rebatimento de surto de desenvolvimento que ocorria no centro-sul do país, organizava-se para articulação de seus interesses (SILVA, 1993, p. 97 98, grifo nosso).
\end{abstract}

A criação da Findes passar por uma série de problemas, Américo Buaiz teve que contar com alguns amigos pessoais para criar a nova entidade, porém segundo ele eram homens de fibra e pessoas motivadas para elevar o grau da cultura e capacidade econômica do Estado, também havia o desejo de colocar o Espírito Santo no mapa da industrialização do país (RAINHA, 2012, p. 61).

Sobre o desejo de industrializar o Estado,

[...] a Federação das Indústrias nasceu de uma vontade enorme que as pessoas tinham de ver o Estado industrializado. Formamos a federação forte pelas idéias e fraca pela representatividade. [...] Hoje, tem um peso muito grande, por que tem indústria para representar. Quando foi fundada, não tinha nem indústrias propriamente ditas, pois foi fundada mais como uma atitude desbravadora (BUAIZ, Apud RIBEIRO, 2013, p. 9).

Após sua criação, a Findes passa a se relacionar de uma forma estreita com o poder público, sempre tentando fazer valer seus interesses. Para Meny (1996), os grupos de interesse são grupos de poder que, mediante formas múltiplas e variadas, procuram fazer valer seus interesses no meio político. Caso claro da atuação da Findes na política capixaba, que com a alternância de poder vai tentando se adequar a cada governo, com o objetivo de se inserir de forma concreta dentro do poder executivo, pois uma vez com esse espaço conquistado, poderia administrar seus anseios como percussora da industrialização no Espírito Santo, bem como lutar pelos seus interesses junto ao governo.

Já Aragão (1994) salienta que a organização dos interesses é a chave para intermediar o mundo privado do mundo público, assegurar privilégios e manter

Em Tese, Florianópolis, v. 12, n. 1, jan./jul., 2015. ISSN: 1806-5023 


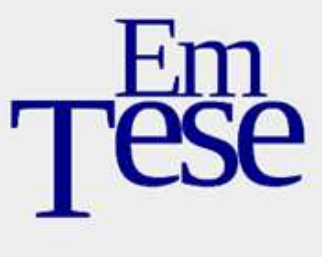

interesses. De fato, a Findes deveria organizar esses interesses, pois deveriam estar alinhados com os interesses do Estado. Para Rainha (2012), os grupos de interesse se distinguem dos demais grupos pela busca de interação com as instituições do Estado e do sistema político. No caso da Findes, ela busca se inserir dentro do poder público capixaba desde a sua gênese em 1958, conseguindo essa inserção total, bem como dar os rumos à economia do Estado, a partir de 1967 como veremos mais adiante.

Fernandes (2006) destaca a associação da burguesia brasileira com o Estado, e para isso, aponta para a relação de interesses criadas pelas associações de classe. Essa relação se desenvolve no terreno político que:

[...] se estabelece o pacto tácito (por vezes formulado e explícito) de dominação de classe. Ao contrário de outras burguesias, que forjaram instituições próprias de poder especificamente social e só usaram o Estado para arranjos mais complicados e específicos, a nossa burguesia converge para o Estado e faz sua unificação no plano político, antes de converter a dominação socioeconômica [...]. As próprias "associações de classe", acima de interesses imediatos das categorias econômicas envolvidas, visavam exercer pressão e influência sobre o Estado (FERNANDES, 2006, p. 240).

Desde a sua formação, a Findes buscava a inserção no aparelho estatal, visando influenciar o Estado capixaba rumo a industrialização, essas associações de classe são compostas por indivíduos que Gramsci (1988), denominava, intelectuais:

\begin{abstract}
Os intelectuais de tipo urbano crescem juntamente com a indústria e são ligados às suas vicissitudes. (...) não possuem nenhuma iniciativa autônoma na elaboração dos planos de construção; colocam em relação, articulando-a, a massa instrumental com o empresariado, elaboram a execução imediata do plano de produção estabelecido pelo estado-maior da indústria, controlando suas fases executivas elementares. Na medida geral, os intelectuais urbanos são bastante estandartizados; os altos intelectuais urbanos confundem-se cada vez mais com o autêntico estado-maior industrial (GRAMSCI, 1988, p.12).
\end{abstract}

A Findes, após a sua formação fica transitando entre governos, ora um governo favorável à industrialização, ora um governo mais agrário. Dentro da perspectiva de Gramsci, podemos perceber como essa relação era contínua e não havia interrupções, 


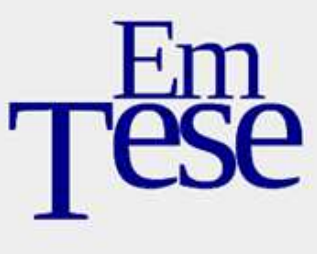

todavia seria equivocado dizer que o novo encerra o velho, muito pelo contrário, no caso capixaba percebemos como essa relação se dá de forma dialética, seguindo uma continuidade histórica, assim:

Cada grupo social essencial, contudo surgindo na história a partir da estrutura econômica anterior e como expressão do desenvolvimento desta estrutura, encontrou categorias intelectuais preexistentes, as quais apareciam, aliás, como representantes de uma continuidade histórica que não fora interrompida nem mesmo pelas mais complicadas e radicais modificações das formas sociais e políticas (GRAMSCI, 1988, p. 5).

Nesse contexto, podemos dizer que os governos capixabas variavam de intelectuais; ora um intelectual tradicional (ligado as elites rurais), ora um intelectual orgânico (ligado a indústria), até que a ditadura militar, a partir de 1964, imprime um caráter altamente tecnicista na forma de governar o país. Com isso, os governos estaduais precisam ter o seu projeto alinhado com os interesses do governo federal.

Como o caráter da administração ${ }^{3}$ de Chiquinho foi pouco alinhado com a industrialização do Estado, podemos concluir que a Findes não teve muito espaço junto ao governo estadual nos seus primeiros meses de existência, tendo em vista que as ideias de Chiquinho estavam na contramão dos propósitos da Findes, que tinha como base um projeto reformista e modernizador, ao passo que Chiquinho via a agricultura como prioridade no seu governo.

Mesmo o governo de Chiquinho tendo como principal plano de trabalho o desenvolvimento da agricultura, Zorzal e Silva (1995), chama atenção para a pequena parcela da sociedade capixaba que surgia em torno da Findes, estes que, buscavam acelerar o processo de industrialização do Estado, mas que também se consolidavam como:

[...] um novo embrião de forças políticas que começaram a ganhar corpo e maior poder de luta, a partir de então. Assim, apesar do reduzido setor industrial existente, nessa época configurou-se um núcleo de forças políticas identificadas com o projeto de industrialização acelerada, a nível nacional, as quais passaram a buscar formas de inserir o Espírito

\footnotetext{
${ }^{3}$ Chiquinho governou o Estado em duas oportunidades, o primeiro mandato foi entre 1954-1958, o segundo mandato foi de 1963-1966.
}

Em Tese, Florianópolis, v. 12, n. 1, jan./jul., 2015. ISSN: 1806-5023 
Santo em tal processo. Essas forças se agregavam em torno da recém criada Federação das Indústrias do Espírito Santo [...] (ZORZAL; SILVA, 1995, p. 359 , grifo nosso)

\section{O segundo governo Lindemberg (1959-1962) e a criação do conselho técnico da Findes}

A Findes realmente não teve espaço no governo de Chiquinho (1954-1958), mas o pleito ocorrido em 1958 contribuiu para que a Findes começasse a dar seus primeiros passos em relação a participação dentro do espectro político capixaba, pois o vencedor do pleito de 1958, foi Carlos Lindemberg, político do PSD que apesar de ser oriundo de família agrofundiária, era mais aberto a industrialização que Chiquinho (ZORZAL; SILVA, 1995).

Com Carlos Lindemberg a frente do executivo capixaba, a Findes, acha espaço para entrar no governo e com o passar do tempo se insere de forma definitiva junto ao parelho estatal, situação que é lembrada pelo próprio Américo Buaiz: "Nós fomos governo durante algum tempo com Carlos Lindemberg” (BUAIZ Apud GURGEL, 1998, p. 23).

Sobre o reconhecimento oficial, consolidação da Findes e sua participação efetiva no governo estadual, Ribeiro (2010) faz a seguinte avaliação:

\footnotetext{
No primeiro ano de sua criação, a Diretoria da Findes buscou o seu reconhecimento oficial, o que ocorreu em 29 de julho de 1958, por carta sindical assinada pelo Ministro dos Negócios do Trabalho da Indústria e do Comércio, Fernando Nóbrega. Era o último ano da primeira administração do governador Francisco Lacerda de Aguiar (1954-1958) e a Findes só iniciaria sua participação efetiva nos rumos da política econômica do Espírito Santo no governo de Carlos Lindenberg (1959-1963) (RIBEIRO, 2010, p. 42).
}

Lindemberg assume o governo em fevereiro de 1959, no contexto da crise do café que se iniciou em meados da década de 1950 e que viria a se agravar no início dos

Em Tese, Florianópolis, v. 12, n. 1, jan./jul., 2015. ISSN: 1806-5023 


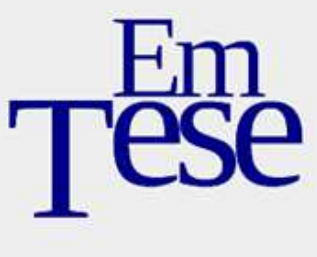

anos 1960, atingindo seu auge no Espírito Santo entre os anos de 1962 e 1967 (OLIVEIRA, 2013).

Carlos Lindemberg, era um político moderado, não era totalmente voltado para a agricultura como Chiquinho, mas também não via apenas na industrialização a única saída para o estado, ou seja, estava entre um extremo e outro. Sua ideia era de conciliar o desenvolvimento agrícola com o industrial, porém a crise do café abre espaço para a modernização da economia estadual e sua inserção no contexto nacional, talvez por uma questão de sobrevivência, Lindemberg, abriu espaço em seu governo para a atuação da Findes (ZORZAL; SILVA, 1995, p. 356).

Sendo assim, Lindemberg inicia sua gestão com o propósito de "recuperar as finanças públicas, apoiar a lavoura e promover uma industrialização moderada a partir do desenvolvimento agrícola" (SILVA, 1993, p. 98). Questão de sobrevivência política ou não, o que sabemos é que a atuação da Findes na gestão de Lindenberg deu um novo fôlego ao seu governo. Não coincidentemente, três meses após a posse de Lindenberg, a Findes cria o seu Conselho Técnico em maio de 1959 com as atribuições de:

[...] estudar os problemas do Estado e fornecer dados sobre a realidade capixaba. A proposta era estudar as dificuldades pelas quais o Estado estava passando e auxiliar os poderes públicos no que se refere à implantação de um projeto de desenvolvimento capitaneado pela industrialização.

Esse Conselho Técnico apoiado pela confederação Nacional da Indústria era formado por Eliezer Batista, Alberto Stange, Arthur Carlos Gerhardt Santos, Humberto Pinheiro Vasconcelos, Aloísio Simões, Jorge Faria Santos, Bolívar de Abreu e o presidente da Federação das Indústrias, Américo Buaiz, que também passaria a presidir o Conselho. Estas pessoas foram citadas pelo jornal A Gazeta como "os mais representativos elementos de classes especializadas”. Dentro em breve, outros empresários também se juntariam ao grupo (GURGEL, 1998, p. 24, grifo nosso).

Surgia no governo Lindenberg, não apenas um reposicionamento de forças políticas, mas, uma articulação para manter o status quo vigente (ZORZAL; SILVA, 1995, p. 378). Dessa forma as forças políticas capixabas lutam agora para uma modernização da economia estadual e sua inserção no contexto nacional, nascendo 


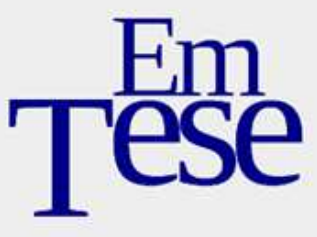

assim, a concepção ideológica do projeto desenvolvimentista que se consolidaria no Estado nos anos 1960/1970.

O Conselho Técnico da Findes tinha como membros:

\begin{abstract}
Eliezer Batista, Alberto Stange, Arthur Carlos Gehardt dos Santos, Humberto Pinheiro Vasconcelos, Aloísio Simões, Jorge Faria Santos e Bolívar Abreu. Batista era engenheiro e superintendente da CVRD. Stange era professor, advogado, escritor e político. Gerhardt era engenheiro do DER. Vasconcelos era coronel do exército e economista. Bolívar era médico sanitarista e secretário de educação do governo Lindemberg. Enfim, tratava-se de um órgão que reunia o que talvez houvesse de melhor na "inteligência" do Espírito Santo naquele momento (SANTOS, 2011, p.158).
\end{abstract}

O Jornal A Gazeta ${ }^{4}$, deu um grande destaque a criação do Conselho Técnico. Como sendo um jornal vinculado ao PSD, a tendência era de que realmente se valorizasse qualquer ato de aliados do novo governo, por exemplo, esse destaque aos conselheiros que são denominados "os mais representativos elementos da classe especializada" (A Gazeta, 22/05/1959, p. 8).

Os conselheiros iam se reunir a cada quinze dias, a fim de colaborar na solução dos sérios problemas locais (GURGEL, 1998, p. 24). Os estudos realizados pelo Conselho Técnico eram direcionados para várias áreas ao mesmo tempo, desde a diversificação da agricultura, passando pela siderurgia, industrialização e geografia industrial, bem como temas como a geração de capitais, ecologia social, ou seja, a ideia ainda era de uma industrialização atrelada à agricultura (SANTOS, 2011).

Como Cronograma de Trabalho, definido na data da instalação, o conselho técnico da Findes estabelece as seguintes diretrizes para o estudo:

- Siderurgia - posição do Espírito Santo em relação à produção nacional; diretrizes a serem tomadas em função da posição geográfica do Estado;

\footnotetext{
${ }^{4}$ Jornal de propriedade da família Lindemberg, era um veículo de comunicação amplamente ligado ao PSD.
}

Em Tese, Florianópolis, v. 12, n. 1, jan./jul., 2015. ISSN: 1806-5023 


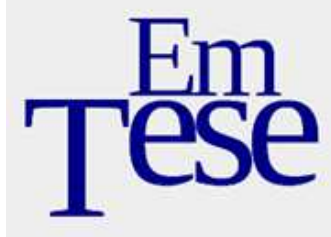

- Geografia Industrial - levantamento de uma carta geo-econômica estadual;

- Agricultura Industrial - tipos de cereais e grãos a serem produzidos com vistas à industrialização;

- Levantamento da Realidade econômico-social do Estado do Espírito Santo ${ }^{5}$.

A prioridade do conselho técnico era produzir o mapeamento das condições geoeconômicas capixabas com vistas a industrializar o Estado. O mais importante desse movimento criado pela Findes foi o avanço de estudos tecnocráticos para o interior do aparelho estatal produzindo assim, modificações para sua estrutura institucional (ZORZAL; SILVA, 1995, p. 360).

A atuação do Conselho Técnico prossegue com o apoio mútuo do governo. A Findes, com o apoio logístico da CNI e apoio político do governo do Estado prepara em 1960:

[...] o SEMINÁRIO PRÓ DESENVOLVIMENTO ECONÔMICO DO ESPÍRITO SANTO, que redundou na elaboração do primeiro diagnóstico sócio-geo-econômico do Espírito Santo, cujo documento síntese recebeu o título de Desenvolvimento Municipal e Níveis de Vida (Serviço Social Rural - 1962) (SILVA, 1993, p. 99).

Um dos reflexos desse seminário foram algumas mudanças realizadas pelo governo do Estado, com o intuito de adequá-lo à nova realidade industrial. Nesse contexto o governo cria o Conselho de Desenvolvimento Econômico (CODEC), que surge no início da década de 1960 com a finalidade de "estudar o desenvolvimento econômico, elaborar planos e programas sobre economia, finanças e as atividades governamentais" (SILVA, 1993, p. 102).

O presidente do Codec era o próprio Lindenberg, além dele, compunham o grupo os secretários de governo, representantes das indústrias, comércio e associações rurais (SILVA, 1993). Podemos perceber que a partir da criação do Codec a

\footnotetext{
${ }^{5}$ (ZORZAL e SILVA, 1995, p. 360).
}

Em Tese, Florianópolis, v. 12, n. 1, jan./jul., 2015. ISSN: 1806-5023 


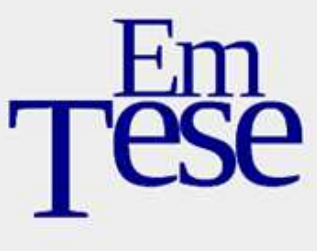

participação dos interesses industriais na política econômica estadual é institucionalizada.

A Findes se mostra bem influente no governo de Lindemberg, a atuação do Conselho Técnico foi fundamental para isso, porém para que a Federação pudesse dar prosseguimento ao trabalho junto ao governo do estado, era necessário que o chefe do executivo tivesse seus interesses alinhados com os interesses da Findes.

Todavia, apesar dos avanços conquistados pela Findes durante o governo Lindenberg e de sua inserção plena no poder público, o pleito 1962 não foi favorável nem a Findes e nem ao PSD. No pleito de 1962, Jones dos Santos Neves era o candidato da Findes, pois no seu governo ele daria uma ênfase especial no processo de industrialização do Estado, não só por isso, mas por que Jones já tinha intenções voltadas para a industrialização desde o seu primeiro governo, além de ser amigo pessoal de Américo Buaiz, então presidente da Findes. Por outro lado tínhamos novamente Chiquinho para concorrer contra o PSD e que, mais uma vez, priorizava o setor agrícola (ZORZAL; SILVA, 1995).

Chiquinho, pela segunda vez, vencia o PSD que mesmo apoiado pela Findes, jornal A Gazeta e pelos empresários, não conseguiu superar o popular candidato, oriundo do Sul Capixaba. Dessa vez, Chiquinho derrotou Jones dos Santos Neves. A Findes, por sua vez, continuaria seus trabalhos, mas sem o apoio do governo.

\section{O segundo governo de Chiquinho, o golpe de 1964 e a inserção da Findes no arcabouço político capixaba}

Chiquinho toma posse em 1963, ano em que João Goulart gozava de plenos poderes na presidência da República, a relação política entre eles era forte (ZORZAL; SILVA, 1995, p. 428), e não apenas isso, durante o governo de Chiquinho o Estado foi

Em Tese, Florianópolis, v. 12, n. 1, jan./jul., 2015. ISSN: 1806-5023 


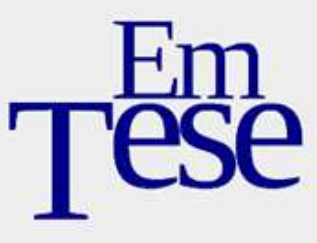

beneficiado com sua ligação com o Governo Federal, pois enquanto Goulart era presidente o governo capixaba, obteve pleno apoio para as realizações do seu plano regional.

Entretanto, Chiquinho também passava por algumas dificuldades, pois o jornal A Gazeta (que não digeriu a derrota de Jones), fazia ferrenha oposição ao seu governo. Desde a sua vitória no referido pleito, A Gazeta, e seus adversários políticos imprimiram uma verdadeira cruzada Anti-Chiquinho, pois este sofria com diversas denuncias de corrupção no seu governo, porém a sorte de Chiquinho, bem como de todo o Brasil mudaria a partir de abril de 1964.

Em $1^{\circ}$ de abril de 1964, militares dão um golpe de estado e depõe do poder o então presidente João Goulart (OLIVEIRA, 2013). Sendo assim, esse evento histórico ainda gera uma série de estudos e teses sobre a sua execução, o que não seria o nosso objetivo analisar no presente trabalho, vamos apenas analisar seus rebatimentos no Espírito Santo.

Sobre seus rebatimentos aqui no Estado, segue a análise Zorzal e Silva:

A ação do governo Lacerda de Aguiar não foi interceptada, imediatamente, após a eclosão do movimento político militar de 1964. A maior parte de seu programa governamental foi implementada nos anos de 1963 e 1964. Entretanto, à medida que o Movimento Revolucionário se consolidou, no Governo Federal, e reorientou os rumos políticos e econômicos da Nação, a ação em curso, no plano estadual, perdeu o ritmo e gradativamente foi desestabilizada (ZORZAL; SILVA, 1995, p. 429).

Oliveira também faz a seguinte ponderação:

Assim, o Golpe militar que se abateu sobre o país em $1^{\circ}$ de abril de 1964 não encontrou, no Espírito Santo, grande resistência por parte daqueles poucos que defendiam o presidente João Goulart e as Reformas de Base. Reproduziu-se, portanto, no Estado, a inoperância dos setores contrários ao Golpe, assim como a inércia da maioria da população à derrubada de Jango, com raras exceções do movimento estudantil, que tentou organizar algumas manifestações [...] ( OLIVEIRA, 2013, p. 103).

Em Tese, Florianópolis, v. 12, n. 1, jan./jul., 2015. ISSN: 1806-5023 


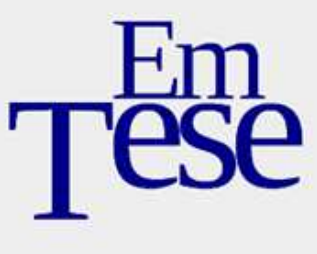

Diante de acusações de corrupção e todas as pressões sofridas por Chiquinho, sua situação fica insustentável, sendo assim, pede licença do governo do Estado no dia $1^{\text {o }}$ de fevereiro de 1966, alegando problemas de saúde. O vice-governador Rubens Rangel assume o governo a partir de então (OLIVEIRA, 2013, p. 136).

Entretanto, o Golpe Militar muda o panorama do Estado brasileiro. Após 1964, o Brasil passou por uma série de transformações de ordem políticas e sociais, porém no campo econômico:

[...] com a tomada do Estado pelo partido orgânico do grande capital, penetramos no contexto do capitalismo monopolista. Para tanto, uniram-se numa nova aliança todos os setores capitalistas, sob a hegemonia do capital estrangeiro, e, com a participação de militares e tecnocratas, instala-se um regime autoritário, em que é anulado qualquer espaço de participação popular, e a participação das classes médias urbanas quase reduz ao plano das aparências (SIQUEIRA, 2010, p. 27).

Segundo a análise de Siqueira, o país passa agora a entrar num contexto do Capitalismo Monopolista, onde os setores capitalistas seriam beneficiados. E como tocar esse projeto industrializante para o país? Além dos militares que instalaram-se no poder, o país necessitava de tecnocratas que seriam o cérebro desse novo modelo de desenvolvimento do Estado Brasileiro.

Como supracitado, após a saída de Chiquinho do executivo capixaba, quem assume o governo é o vice Rubens Rangel, com isso a Findes retoma seu espaço no poder público capixaba. O governo Rubens Rangel é curto (1966-1967), porém o mesmo é primordial para que se compreenda como as principais forças políticas do Estado se acomodaram e se posicionaram com a mudança do comando no governo.

A crise envolvendo o afastamento de Chiquinho traz de volta a cena política a Findes, bem como o PSD, que fora alijado das decisões no cenário político capixaba após a derrota de Jones dos Santos Neves. No período do segundo governo de Chiquinho, o papel do PSD era de uma oposição ferrenha ao governo, comandada na época pelo jovem deputado Christiano Dias Lopes. Todavia, com Rubens Rangel no

Em Tese, Florianópolis, v. 12, n. 1, jan./jul., 2015. ISSN: 1806-5023 


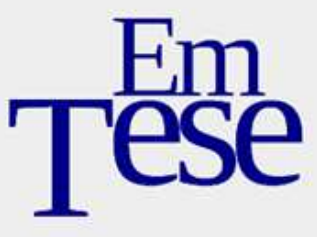

poder ocorre uma aproximação com o PSD e sua ala mais conservadora, justamente liderada por Dias Lopes, que representava os setores urbano-industriais (OLIVEIRA, 2013, p. 136).

Contudo, a mudança política e a reinserção da Findes no cenário político capixaba ocorre ainda na gestão de Rubens Rangel. Rangel convoca Arthur Carlos Gerhardt Santos para uma reunião, onde o convida para fazer parte do seu governo, junto com outros tecnocratas da Findes. A ideia de Rangel era de colocar tecnocratas nas secretarias, alijando assim os políticos desse processo, em suma, a sua ideia era “deixar a casa limpa” para o próximo governo (OLIVEIRA, 2013, p. 140).

\section{A eleição de Dias Lopes e a atuação da Findes durante seu governo}

Com os militares no poder as eleições passaram a ser indiretas, esse critério foi imposto pelo novo governo através do Ato Institucional $n^{\circ} 3$. Para os cargos de Presidente, governadores, prefeitos de capitais e áreas de segurança nacional não havia mais eleições diretas e também foi extinto o multipartidarismo, sendo imposto pelos militares o bipartidarismo, onde o sistema eleitoral brasileiro agora seria representado por apenas dois partidos: Aliança Renovadora Nacional (ARENA), partido aliado ao governo e o Movimento Democrático Brasileiro (MDB), partido de oposição (OLIVEIRA, 2013, p. 142).

Como nosso estudo é regional, vamos nos ater as eleições para o governo do Estado que ocorria da seguinte forma:

[...] a escolha seguia, basicamente, três etapas: $1^{\circ}$ ) ocorria um amplo debate no interior do partido governista, a Arena, entre as principais lideranças e/ou grupos, para a confecção de uma lista ou indicação de um nome, se fosse alcançado o consenso; $2^{\circ}$ ) em seguida, a lista escolhida era submetida ao Presidente da República para a indicação de sua preferência; $3^{\circ}$ ) em seguida, o nome era remetido à assembléia Legislativa do Estado, para ser aprovado. (OLIVEIRA, 2013, p. 25).

Em Tese, Florianópolis, v. 12, n. 1, jan./jul., 2015. ISSN: 1806-5023 
Sobre a eleição de Dias Lopes:

Dias Lopes é o primeiro Chefe do Poder Executivo Estadual que chega ao cargo por via da eleição indireta havida na Assembléia Legislativa, por força do Ato Institucional $\mathrm{n}^{\mathbf{0}} 2$, baixado pelo Regime Militar que se instaurou no país em 1964. Dias Lopes (conforme entrevista ao autor), era formado em Direito e foi oficial de Gabinete de Jones dos Santos Neves, de quem era grande admirador. Oriundo do PSD, ocupa o cargo de Deputado Estadual, a partir de 1954, ininterruptamente, até tomar posse como Governador do Estado (SILVA, 1993, p. 89).

Segundo a visão do próprio ex-governador Dias Lopes, a sua indicação começa a partir de sua atuação como líder da oposição ao governo Lacerda de Aguiar, além disso, havia seu relacionamento pessoal com o Coronel Guilhermano Monteiro, esse que era elemento do gabinete Militar da Presidência da República, destacado para acompanhar fatos políticos do Espírito Santo, ou seja, Dias Lopes além de possuir perfil urbanoindustrial desejado pela ditadura, era um político bem relacionado e bem visto pelos militares (OLIVEIRA, 2013).

Sobre o perfil de Dias Lopes e o seu alinhamento com o regime militar:

[...] convém lembrar que Dias Lopes havia participado ativamente da elaboração do plano de governo do candidato Jones, sua principal referência política, que foi derrotado por Chiquinho em 1962. Portanto, como já salientado, estava alinhado com os objetivos modernizantes e industrializantes esboçados por parcelas da elite capixaba, especialmente, aqueles verificados na gestão Jones. Além disso, aderia ao perfil desejado pelo Regime Militar em termos de projeto de desenvolvimento econômico (OLIVEIRA, 2013, p. 156).

Retomando uma leitura mais contemporânea de Gramsci, podemos dizer que

Dias Lopes era o tipo de intelectual que:

[...] representa a burguesia em seu avanço no desenvolvimento de focas produtivas. Estão ligados ao processo de desenvolvimento do capital no âmbito das relações de produção capitalistas (desenvolvimento da atividade industrial e comércio em geral). São, deste modo, responsáveis por tecerem "planos" para aperfeiçoar o desenvolvimento das relações capitalistas e por justificá-las (ideologicamente) de forma que tais relações sejam tomadas consensualmente como naturais e legítimas (SOUZA, 2009, p. 19) 
Fragmentos do discurso de posse de Dias Lopes e sua gana em industrializar o Estado, demonstram como ele era alinhado com as elites industriais, bem como na avaliação de Gramsci se configurava como um típico intelectual orgânico, alinhado com uma elite econômica advinda da Findes:

\begin{abstract}
Pretendemos, apenas, marcar o governo pelo sentido da mudança; mudança nos métodos da administração pública; mudança nas atitudes diante dos problemas no Estado; mudança no comportamento diante das nossas potencialidades adormecidas; mudanças nas perspectivas de desenvolvimento do nosso Estado [...] criaremos novas fontes de sustentação econômica. [...] Para essa dinamização da economia estadual, sem qualquer preocupação de obter resultados imediatos, objetivando repercussões eleitorais, nosso plano de governo embasa-se no binômio: racionalização administrativa e desenvolvimento $[\ldots]^{6}$. (Grifo nosso)
\end{abstract}

Outros fragmentos do discurso de posse de Dias Lopes demonstram também esse alinhamento com o regime militar, bem como o seu perfil empreendedor para colocar o Estado no Mapa da Industrialização do Brasil:

\begin{abstract}
O primeiro termo da equação compreende ampla reforma administrativa, não limitada apenas a uma estrutura nova, mais leve, mais arejada, mais descentralizada e mais dinâmica; a reforma abrangerá, ainda, providências inflexíveis para prosseguir o processo de saneamento iniciado no Governo Rubens Rangel, em moldes a que se possa restabelecer, em sua plenitude, o primado da responsabilidade, austeridade e da autoridade nos atos do governo [...]. No segundo termo do binômio programático, estarão compreendidas todas as providências destinadas a ordenar esforços e recursos capazes de criar condições mínimas necessárias afim de que o Estado possa decolar no rumo de seu efetivo desenvolvimento econômico. [...] não temos dúvidas de que as melhores perspectivas para o processo de aceleração de nossa economia encontram-se nas atividades dinâmicas ligadas à exportação de minério e à agricultura de abastecimento ${ }^{7}$. (Grifo nosso)
\end{abstract}

O que podemos perceber com esses fragmentos do discurso de Dias Lopes? Primeiro, que suas ideias estavam aparelhadas com o regime militar, ou seja, ideia de modernizar o Estado; segundo, conseguimos detectar como esse processo de saneamento, iniciado no governo de Rubens Rangel, foi modelo para o início do governo de Dias Lopes (assunto que trataremos com mais cuidado adiante); por último

\footnotetext{
${ }^{6}$ ESPÍRITO Santo tem novo Governador: discurso. Revista Capixaba, No 1, Ano I, Vitória, mar. 1967, p.15

${ }^{7}$ ESPÍRITO Santo tem novo Governador: discurso. Revista Capixaba, No 1, Ano I, Vitória, mar. 1967, p. 15
} 


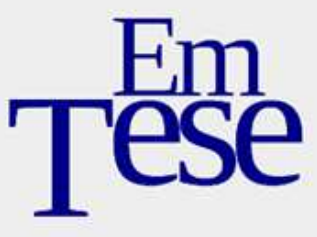

conseguimos concluir que foi no seu governo que o Espírito Santo inicia de fato seu processo de industrialização, processo esse que tentou ser implementado por Jones dos Santos Neves, sem sucesso.

Como Dias Lopes poderia colocar esse processo de industrialização em prática? Essencialmente, esse processo não poderia ser realizado sozinho ou apenas com o apoio de sua base política, mas Dias Lopes precisava estreitar sua relação com o empresariado capixaba, uma vez que este estava alocado no interior da Findes.

Nesse sentido, Dias Lopes utiliza a estratégia de se aproximar da Findes, onde busca apoio técnico e financeiro para viabilizar o seu projeto desenvolvimentista. Seria apenas com o apoio da Findes que ele conseguiria executar o binômio citado em seu discurso: racionalização administrativa e desenvolvimento (RAINHA, 2012, p. 64).

A racionalização administrativa ele consegue a partir do momento que a Findes passa a fornecer os quadros técnicos para atuar no seu governo, tanto nas secretarias como nas autarquias. Todo plano de governo de Dias Lopes é baseado na elaboração de um estudo denominado Diagnóstico para o Planejamento Econômico do Espírito Santo, produzido pelo Instituto de Estudos para o Desenvolvimento Social e Econômico, esse diagnóstico foi um estudo encomendado pela Findes para dar suporte e nortear o projeto desenvolvimentista de Dias Lopes (GURGEL, 1998, p. 50).

Apesar de se consolidar com Dias Lopes, essa racionalização administrativa se inicia ainda no governo de Rubens Rangel como citado anteriormente. Rangel decide fazer uma "limpeza administrativa" no pouco tempo de governo que tinha, com a pretensão de deixar a "casa arrumada" para seu sucessor, buscando assim na nomeação de uma equipe técnica, a solução para acertar as contas do governo, uma vez que, ele sabia que não conseguiria fazer isso com uma equipe política em seu secretariado, assim, ele nomeia tecnocratas como Alvino Gatti e Arthur Carlos Gerhardt Santos (OLIVEIRA, 2013, p. 166).

Em Tese, Florianópolis, v. 12, n. 1, jan./jul., 2015. ISSN: 1806-5023 
O secretariado de Dias Lopes é todo oriundo da Findes, o que se configura numa equipe altamente técnica - dentro do seu secretariado não havia políticos - somente os ditos tecnocratas, o que racionalizava a administração e atendia aos interesses urbanoindustriais, atendendo ao mesmo tempo os interesses da Findes, que tendo quadros importantes dentro das secretarias, poderia se articular para buscar privilégios junto ao governo:

\begin{abstract}
A federação das indústrias, desse modo, influenciou diretamente na indicação do secretariado recém-eleito do Governador, além de participar dos quadros do governo com diversos indivíduos oriundos da Findes. Entre os principais nomes que despontaram por ocasião da montagem da equipe de Dias Lopes, estão figuras como Darcy Werthler Vervloet (Educação), Rubens Paiva de Oliveira (Fazenda), Antônio Dias de Sousa (Governo), Hamilton Machado de Carvalho (Saúde), Alvino Gatti (Planejamento), Arthur Carlos Gerhardt Santos (Secretaria sem Pasta para o Planejamento e Secretário de Viação e Obras Públicas entre 1966 e 1967), entre outros nomes, todos quadros eminentemente técnicos e boa parte ligada à Federação das Indústrias. Em parte das autarquias, a equipe contou com vários diretores da gestão anterior, em grande medida também com perfis técnicos (OLIVEIRA, 2013, p. 166-167, grifo nosso).
\end{abstract}

Para prosseguir com o seu projeto de forma sólida, Dias Lopes precisava obter recursos federais, nesse sentido, o único grupo social forte o suficiente para apoiar política e financeiramente seu projeto estava dentro da Findes. Dias Lopes percebe a força da Findes e usa isso em seu favor, porém, ao aproximar-se da Findes, ele teria que atender aos interesses da própria Federação, o que lhe custou um desgaste político a ponto de ter que se defender da insinuação de ser um governador da Findes (GURGEL, 1998, p. 48).

Ainda sobre a participação da Findes no governo Dias Lopes e a formação do corpo técnico:

A atuação da Findes foi intensa durante o governo de Christiano Dias Lopes, primeiro, por que o próprio governador acreditava na alternativa da industrialização e, segundo por que a conjuntura econômica (decadência da economia cafeeira) favorecida. A Findes teve uma participação não só apoiando estudos técnicos, mas também participando do governo: dos 28 conselhos existentes na administração pública, a Findes estava representada diretamente em 10 e indiretamente em 7. Tendo representação em mais da metade dos conselhos e ainda através do contato pessoal com o governador 
(que visitava a casa dos industriais para "esclarecimentos públicos à categoria") a entidade mantinha uma posição privilegiada com acesso a informação e possibilidade de influenciar as políticas públicas. Sem contar que grande parte dos cargos nos órgãos de governos era ocupada por técnicos que haviam saído da entidade (RAINHA, 2012, p. 65).

Diante dessas fontes, podemos perceber como o primeiro elemento do binômio, a racionalização administrativa estava altamente atrelada a Findes, pois a mesma passa a agir com um papel propositivo e técnico para a gestão de políticas públicas, passando assim a fornecer importantes quadros governamentais ao Estado. Nesse sentido essa racionalização vem exatamente nomear quadros técnicos onde teoricamente deveriam estar quadros políticos.

Quanto ao segundo elemento do binômio, o desenvolvimento, podemos destacar que:

O Governador Christiano Dias Lopes Filho adotou o DIAGNÓSTICO PARA O PLANEJAMENTO ECONÔMICO DO ESTADO DO ESPÍRITO SANTO como Plano de Governo. Note-se que todo o seu conteúdo está voltado para o desenvolvimento econômico como fator predominante para a solução da crise por que passava o Estado do Espírito Santo com a derrocada da lavoura cafeeira. E uma ênfase muito grande foi dada aos órgãos relacionados com o dito desenvolvimento econômico, com orientação e atuação locais, como uma forma de criar os meios para a alavancagem econômica da região (SILVA, 1993, p.114).

Dias Lopes assume formalmente que o seu Plano de Governo se fundamenta no Diagnóstico para o Planejamento Econômico do Estado do Espírito Santo. Tanto que o seu discurso de posse, onde ele resume seu plano, era uma síntese do referido trabalho (SILVA, 1993, p. 107). O diagnóstico, além de ter sido financiado pela própria Findes, apresentava para o momento uma série de variáveis, um cruzamento de diversos fatores que influenciariam no processo: o Governo Federal, a ação política da Findes, a Crise do Café e a própria crença do governador no projeto.

O Diagnóstico para o Planejamento Econômico do Estado do Espírito Santo levanta as seguintes questões:

Em Tese, Florianópolis, v. 12, n. 1, jan./jul., 2015. ISSN: 1806-5023 
O Plano disseca as características econômicas do Estado (renda interna, transportes, energia elétrica) e levanta a evolução recente do conjunto do Estado, da estrutura industrial e das zonas fisiográficas; analisa as atividades dinâmicas e tradicionais: café, cacau, açúcar e madeira; analisa, ainda, as atividades dinâmicas ligadas à exportação de minérios e à agricultura de abastecimento; contempla o alargamento das potencialidades dinâmicas relacionadas com as rodovias federais BRs 101, 259 e 262; avalia órgãos regionais de desenvolvimento e apresenta sugestões para um programa de investimentos (SILVA, 1993, p. 108).

Após verificar a capacidade de alavancagem financeira das atividades econômicas tradicionais desenvolvidas no Estado, o referido estudo chega a seguinte definição sobre cada um:

- O Café - Apesar de ser o principal produto do Estado, estava em plena crise e no meio do programa de erradicação;

- O Cacau - Além das oscilações do mercado internacional, encontrava limitações de fatores naturais - solo e clima.

- O Açúcar - enfrentava a excessiva produção do país, especialmente do desenvolvimento da indústria paulista, não valia a pena tentar iniciar uma concorrência;

- A Madeira - Dada sua exploração predatória conduzida historicamente no Estado, já mostrava claros sinais de esgotamento ${ }^{8}$.

A solução sobre os referidos produtos é de que nenhum deles oferece uma perspectiva econômica animadora. Então, qual foi o entendimento final do referido Diagnóstico? A conclusão é de que as atividades econômicas identificadas como capazes de dinamizar a produção de bens e serviços no seu estado eram: a exportação de minério de ferro e a agricultura de abastecimento, exatamente os dois pontos que Dias Lopes cita em seu discurso de posse.

Contudo, o papel da Findes no governo de Dias Lopes não se limita apenas na composição de quadros técnicos, mas ela passa a agir de uma forma mais acentuada nas

\footnotetext{
${ }^{8}$ Dados extraídos (SILVA, 1993, p. 110).
}

Em Tese, Florianópolis, v. 12, n. 1, jan./jul., 2015. ISSN: 1806-5023 


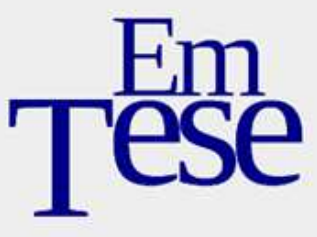

formulações de políticas econômicas para o estado. Tanto que, no segundo ano do Governo Dias Lopes a Findes prepara outro simpósio, com os mesmo moldes do que fora realizado em 1959:

O Simpósio trouxe a Vitória autoridades federais o que deu visibilidade aos problemas do Espírito Santo. Em decorrência da articulação entre elite local e o sistema político nacional, foi promulgado o Decreto Federal 880/69, autorizando incentivos financeiros que viabilizaram seu desenvolvimento (RAINHA, 2012, p. 65-66).

Concluindo sobre o papel da Findes no Governo Dias Lopes:

[...] a Findes atuava em várias frentes. Por conta desse papel propositivo e técnico para a gestão de políticas públicas, que passou a desenvolver, mais o fornecimento de importantes quadros governamentais ao Estado, a partir da sua criação [...] (OLIVEIRA, 2013, p. 166).

\section{Considerações finais}

Após as eleições de 1947, ocorre uma série de alternâncias no governo do Espírito Santo, perpassando pelo golpe militar, implantação do bipartidarismo e eleições indiretas. Após a consolidação das eleições indiretas, Christiano Dias Lopes assume o governo em 1967, desde então, a Findes se insere de forma definitiva no arcabouço político capixaba.

Antes de assumir o governo, Dias Lopes contata a Findes e solicita que ela encomende um estudo sobre os problemas sociais e econômicos do Estado, esse estudo é financiado pela Findes e se chama: Diagnóstico para o Planejamento Econômico do Estado do Espírito Santo, esse diagnóstico faz um levantamento completo dos problemas econômicos do Estado. No seu discurso de posse, Dias Lopes usa os resultados desse estudo como o seu plano de governo para o Estado, seguindo assim o binômio que ele mesmo denominou: racionalização administrativa e desenvolvimento. 


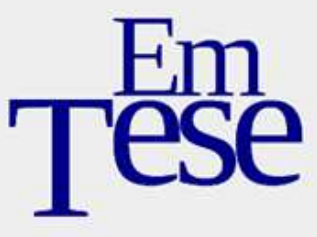

Concluímos dessa forma que ambos os binômios estavam ligados diretamente a Findes. Veja que, a racionalização da administração vem através da indicação de quadros técnicos da Findes para os altos cargos estaduais, secretarias, autarquias, além de integrar os diversos conselhos criados para planejar ou dirigir a política desenvolvimentista do Espírito Santo, como a Suppin, Codes e Codec. O desenvolvimento estava ligado ao resultado do Diagnóstico, que apontava a industrialização como a única solução para o desenvolvimento do estado, e que esse caminho deveria ser traçado através da exportação de minério de ferro e da agricultura de abastecimento, buscando assim meios de trazer ao Espírito Santo recursos vindos do Governo Federal.

Corroboramos também das hipóteses supracitadas de Gramsci (1988), pois como vimos, a organização dos intelectuais na sociedade ocorre em função de garantir seus próprios interesses, no caso da Findes, Américo Buaiz cria a entidade com o intuito de desenvolver a indústria no Estado do Espírito Santo. Assim, a Findes passa a se organizar sempre buscando o aparelhamento com o poder público, visando ter seus interesses atendidos. Analisando a trajetória do Espírito Santo desde a fundação da Findes, podemos perceber como o processo de mudança de um governo para o outro se configurava como um entrave nos planos da Findes, pois nem todos os governantes tinham seu projeto voltado para a industrialização do Estado.

Todavia, o golpe militar e o caráter tecnicista do regime abrem espaço para que a Findes se aloque no interior do arcabouço político capixaba, compondo junto com o Governo Dias Lopes, uma equipe altamente técnica e voltada para o desenvolvimento do Estado através da industrialização.

Após essas constatações compartilhamos da hipótese de Oliveira (2013) que avalia a Findes como uma espécie de proto partido político, servindo como um lócus de recrutamento e como formador de quadros políticos que acabaram servindo como sustentação política no Espírito Santo, principalmente no que tange ao seu processo de

Em Tese, Florianópolis, v. 12, n. 1, jan./jul., 2015. ISSN: 1806-5023 


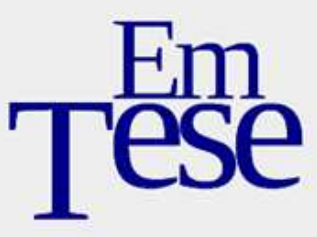

industrialização. Essa inserção no executivo capixaba se dá de forma mais acentuada no governo de Dias Lopes e perpassa por todo o Regime Militar durante o mandato de cada governador capixaba no período. Desse modo, compreendemos como os interesses da Findes estavam alinhados com o projeto desenvolvimentista dos militares, o que insere a Findes e os seus intelectuais de uma forma expressiva no arcabouço do executivo capixaba.

Essa relação entre Regime Militar, Findes e Dias Lopes é o que chamamos de uma CONVERGÊNCIA DE INTERESSES, ou seja, os interesses estavam atrelados e se convergiram no processo político durante o regime militar, esses três elementos estavam completamente ligados por um ideal comum: a industrialização. A Findes se alia ao governo para conseguir benefícios e industrializar o Estado, Dias Lopes se alia a Findes para conseguir alcançar seus objetivos, a ponto de alijar políticos de seu partido para atender aos interesses da Findes, e ambos estavam conectados ao caráter industrializante do Regime Militar.

Contudo, a Findes não estava envolvida de forma direta apenas no governo de Dias Lopes, mas também esteve presente em todos os governos capixabas durante o Regime Militar, porém "apesar de todos os governos militares terem uma ligação com a Findes, o período mais emblemático da atuação da entidade junto ao poder público ocorre durante o governo Christiano Dias Lopes" (RAINHA, 2012, p.66).

Francisco Aurélio Ribeiro que foi responsável por registar oficialmente a história da Findes e destaca que:

[...] o bom relacionamento existente entre a Findes e os governadores indicados no período militar: Christiano Dias Lopes Filho (1967-1970), Arthur Carlos Gerhardt Santos (1971-1975), Elcio Álvares (1975-1978) e Eurico Rezende (1979-1982). Arthur Gerhardt, sucesso de Christiano Filho, era engenheiro e trabalhou na Findes como conselheiro técnico desde a sua criação, em 1958. Élcio Álvares e Eurico Rezende foram advogados da Findes. Christiano Dias Lopes tivera seu o "Diagnóstico para o Planejamento Econômico do Espírito Santo" pago pela Findes. Assim, desde o governo de Carlos Lindemberg [com exceção do governo Lacerda de Aguiar], passado pelo de Christiano Dias Lopes Filho, a Findes passou a integrar os diversos

Em Tese, Florianópolis, v. 12, n. 1, jan./jul., 2015. ISSN: 1806-5023 
conselhos criados para planejar ou dirigir a política desenvolvimentista do Espírito Santo, como a Suppin, Codes, Codec, entre outros, bem como participou do governo estadual como técnico do seu quadro de profissionais (RIBEIRO, 2010, p. 59).

Concluindo, esse artigo procurou contribuir para investigar a interface da participação da Findes no executivo capixaba, chegando ao entendimento através da tese de Oliveira (2013), que a Findes funcionou como suporte para o executivo capixaba, principalmente a partir da eleição de Dias Lopes, perpassando por todo o regime militar, pois a primazia da industrialização estava em suas mãos, bem como o poder econômico e o conhecimento técnico, ou seja, não havia como conduzir o Estado à industrialização sem o apoio da Findes.

Nesse sentido a Findes passa a nortear o executivo capixaba em três aspectos: 1 Formular estudos de forma que pudesse viabilizar a industrialização do Estado; 2 Apoio Financeiro e Logístico; 3 - Fornecer quadros técnicos capazes de potencializar esse processo de industrialização que o Espírito Santo tanto precisava. Dessa forma o Estado do Espírito Santo sai de uma posição completamente desfavorável para iniciar, na década de 1970, um processo de industrialização rápido e bem elaborado. Esses quadros técnicos oriundos da Findes atuavam tanto na área de administração e planejamento, como dentro do próprio executivo, pois chegaram ao cargo político mais alto no Estado, sendo chefes do executivo capixaba Arthur Carlos Gerhardt, Elcio Alvares e Eurico Rezende, respectivamente.

\section{Referências}

ARAGÃO, Murillo de. Grupos de pressão no Congresso Nacional. São Paulo, Maltese, 1994.

FERNANDES, Florestan. A revolução burguesa no Brasil: ensaio de interpretação sociológica. São Paulo: Globo, 2006.

Em Tese, Florianópolis, v. 12, n. 1, jan./jul., 2015. ISSN: 1806-5023 


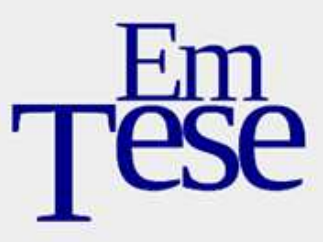

GRAMSCI, Antonio. Os intelectuais e a organização da cultura. Rio de Janeiro: Civilização Brasileira, 1988.

GURGEL, A. de Pádua. A Federação das Indústrias e o Desenvolvimento. Vitória, Contexto Jornalismo \& Assessoria Ltda./Findes, 1998.

MÉNY, Ives. Politique comparée. Lesdémocraties Allemagne. États-Unis, France, Grande-Bretagne; Italie. Paris, Monchrestien, 5eédition, 1996.

OLIVEIRA, Uéber José de. Configuração Político-Partidária do Estado do Espírito Santo no contexto do Regime Militar: Um estudo regional acerca das trajetórias de arena e mdb (1964-1982). Tese (Doutorado em Ciência Política) - Programa de PósGraduação em Ciência Política. Universidade Federal de São Carlos. São Carlos. 2013.

RAINHA, Jamilla. Articulação de interesses entre o setor privado e poder público: $O$ movimento empresarial Espírito Santo em ação e o governo do Estado do Espírito Santo. Dissertação (Mestrado em Ciências Sociais) - Programa de Pós-Graduação em Ciências Sociais. Universidade Federal do Espírito Santo. Vitória. 2012.

RIBEIRO, Francisco Aurélio. FINDES 50 anos: A História da Federação das Indústrias do Estado do Espírito Santo. Vitória: Findes, 2010.

SANTOS, Estilaque Ferreira dos. Memória do Desenvolvimento do Espírito SantoGrandes Nomes - Américo Buaiz. Editora GSA: Vitória-ES, 2011.

SOUZA, Alan. R.. O estado moderno e o papel dos intelectuais em Gramsci. Veronotio Revista OnLine, n. 10, ano V. São Paulo, outubro, 2009.

SILVA, Justo. Corrêa. Espírito Santo: o processo de industrialização e a formação da estrutura do poder executivo - 1967/1983. Dissertação (Mestrado em Administração) Programa de Pós-Graduação em Administração. Universidade Federal de Minas Gerais. Belo Horizonte. 1993.

Em Tese, Florianópolis, v. 12, n. 1, jan./jul., 2015. ISSN: 1806-5023 


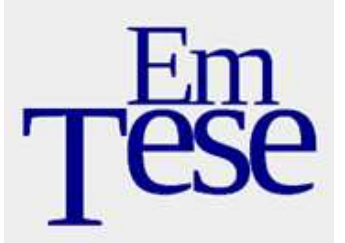

SIQUEIRA, Maria da Penha Smazaro. Industrialização e empobrecimento urbano: o caso da Grande Vitória (1950-1980). Vitória: Edufes, 2001.

ZORZAL E SILVA, Marta. Espírito Santo: Estado, interesses e poder. Vitória: FCAA, SPDC, 1995.

Em Tese, Florianópolis, v. 12, n. 1, jan./jul., 2015. ISSN: 1806-5023 


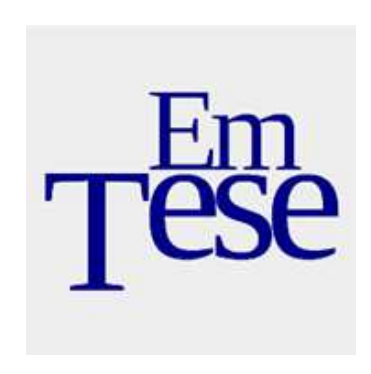

\title{
Relação entre a Federação das Indústrias do Espírito Santo e o governo de Christiano Dias Lopes (1967-1971)
}

\begin{abstract}
Resumo: O presente artigo trata da Federação das Indústrias do Espírito Santo (Findes), sua criação, relação de interesses e envolvimento com poder público capixaba. Todavia, o foco é tratar da Findes no Governo de Christiano Dias Lopes (1967-1971), que foi o primeiro governador biônico do Estado, e como os interesses da Findes convergiam com os interesses dos militares, que governavam o Brasil desde o golpe de 1964. Nosso referencial é Gramsci (1988) que destaca a importância dos intelectuais na formação da indústria e sua influencia na industrialização, porém o problema se forma a partir da hipótese de Oliveira (2013), da qual corroboramos e mostramos no decorrer do artigo; que a Findes funcionou no regime militar como uma espécie de proto partido político indicando quadros que no decorrer do Regime, foram chefes do executivo capixaba.
\end{abstract}

Palavras-chave: Espírito Santo. Findes. Interesse.

\section{Relationship between the Federation of Industries of the Holy Spirit and the Christiano Dias Lopes government (1967-1971)}

\begin{abstract}
This article deals about the Federation of Industries of the Espírito Santo State (Findes), your creation, relation of interest and relationship with capixaba government. However, the focus is to deal with Findes in the Government of Christiano Dias Lopes (1967-1971), who was the first bionic governor of the Espírito Santo State, and how the interests of Findes converged with the interests of the militaries, who ruled Brazil since the coup 1964. Our theoretical basis is Gramsci (1978) which highlights the importance of intellectuals in industry training and its influence on industrialization, but the problem is formed by the Oliveira hypothesis (2013), of which we agree and show throughout the article; Findes worked in the military regime as a kind of proto political party indicating tables during the regime, were heads of Espirito Santo State.
\end{abstract}

Keywords: Espírito Santo State. Findes. Interest.

Recebido em: 16 de abril de 2015

Aceito para publicação em: 23 de maio de 2015

Em Tese, Florianópolis, v. 12, n. 1, jan./jul., 2015. ISSN: 1806-5023 